\title{
Iranian participatory research impacts: A knowledge translation perspective
}

\author{
Nina Loori ${ }^{1}$, Jamal Ahmadzadeh², Kazhal Mobaraki ${ }^{2}$, Ensiyeh Jamshidi ${ }^{1,3 *}$, Nasrin Hossein Gholizadeh ${ }^{3}$ and Reza Majdzadeh $^{4}$ \\ ${ }^{1}$ Community Based Participatory Research Center, Iranian Institute for Reduction of High-Risk Behaviors, Tehran University of Medical Sciences, Tehran, Iran \\ ${ }^{2}$ Social Determinants of Health Research Center, Urmia University of Medical Sciences, Urmia, Iran \\ ${ }^{3}$ Department of Health Education and Promotion, School of Public Health, Tehran University of Medical Sciences, Tehran, Iran \\ ${ }^{4}$ Knowledge Utilization Research Center, Tehran University of Medical Sciences, Tehran, Iran
}

\begin{abstract}
Purpose: The aim of this study is to examine the impacts of Iranian participatory research in practice.

Materials/methods: A review of participatory studies conducted to find out published articles (Persian or English) in Iran. The keywords "knowledge translation, knowledge utilization, participatory research, participatory action research, outcome assessment, impact assessment, results" were searched in several domestic and international databases such as Pubmed, Medline, Embase, Iranmedex, SID and Iranpsych. This study included papers published during 2006-2008, to ensure that enough time (ten years) had passed for changes to track the short and long-term effects of researches in the next part as a cross-sectional study.

Results: The findings of the cross-sectional study indicated that the greatest changes occurred at participation (92.3\%) and empowerment (76.9\%) levels in people/ patients; participation and capacity building $(38.5 \%)$ in researchers; participation and awareness $(30.8 \%)$ in health care providers groups of stakeholders. Also, the highest scores were attributed to inter-sectoral collaboration $(38.5 \%, 53.8 \%)$ and decision-making $(30.8 \%, 38.5 \%)$ in health policy-makers and organizational managers, respectively.

Conclusions: Community-based participatory research can have a great impact on community participation in the research process, as well as on capacity building and knowledge sharing among researchers. It can also have moderate effects on improving managerial decision-making and inter-sectoral collaboration among organizational managers.
\end{abstract}

\section{Introduction}

Community-based participatory research (CBPR) and Knowledge Translation (KT) are approaches to research that make contributions to the practice [1]. The main purpose of the KT process is to bridge the know-do gap, ensuring that research is used to improve health outcomes [2]. Better use of research knowledge in practice takes place within a complex system of interactions and partnerships between researchers and knowledge users [1].

CBPR presumes that social changes can be facilitated by involving partners who are affected by the issue and empowering them at various stages, from the definition of the research question to the interpretation and publication of the results [3-5].

Iran is one of the first developing countries adopting the CBPR approach to address public health. So, several studies have conducted by different organizations from 2001 [6-11]. Whether participatory research and other types of research can create changes has always been a concern [12].

A few studies conducted to examine the impacts of health research in the realms of capacity-building, decision-making, health and economics [13-16]. The only study carried out employing the Payback model to assess the effectiveness of health research in Iran demonstrated that $59.7 \%$ of studies caused changes in the areas of local decision-making (29\%), executive organizational instructions, rules or guidelines (16.3\%), systematic reviews (12\%), and clinical or public health guidelines (11.7\%) [17].

Since there are limited studies on the effects of participatory research knowledge translation in practice, this study aimed to answer the following questions:

1. What kinds of changes in practice are reported by corresponding authors of participatory research studies?

2. What are the barriers and solutions to apply research results in practice?

3. The results of this study can provide recommendations to use participatory research for making a change in the fields of community participation, policy-making, health-care service delivery, and management.

${ }^{*}$ Correspondence to: Ensiyeh Jamshidi, 9th Unit, 7th Floor, No.1547, Tehran University of Medical Sciences' Research Center Building, North Kargar St., Enghelab Sq., Tehran, Iran, Tel: +98 912712 2938; Fax: +98 21 88995880-79; E-mail: ensiyeh_jamshidi@yahoo.com

Key words: knowledge translation, community-based participatory research, research impact, Iran

Received: June 11, 2020; Accepted: July 01, 2020; Published: July 06, 2020 


\section{Methods}

A review of participatory studies conducted to find out published articles (Persian or English) in Iran. The keywords "knowledge translation, knowledge utilization, participatory research, participatory action research, outcome assessment, impact assessment, results" were searched in several domestic and international databases such as Pubmed, Medline, Embase, Iranmedex, SID and Iranpsych. This study included papers published during 2006-2008, to ensure that enough time (ten years) had passed for changes to track the short and longterm effects of researches in the next part as a cross-sectional study.

First, all retrieved articles were scanned by title and any irrelevant studies were removed. Next, two independent reviewers assessed the abstracts of studies for inclusion in the cross-sectional study. The the text of remaining papers were examined in terms of compliance with 10 participatory research principles $[18,19]$. The reviewed studies that met 70 percent of CBPR principles were included. In cases of dispute between the two reviewers, consensus were reached through negotiation.

A cross-sectional study was carried out to examine the effects of retrieved participatory research studies in practice. The samples consisted of the corresponding authors of those papers publishing during 2006-2008. The reason for the selection of these authors was the availability of their e-mail address and contact information. The sample size was equal to the number of papers compiled in the study, meeting the inclusion criteria $(n=28)$. Due to a lack of access and collaboration, and changing phone numbers and e-mails contained in the papers, ultimately a total of 13 subjects completed the questionnaires and participated in the subsequent interviews.

A self-administrated questionnaire containing open and closed items designed on the basis of the literature review. The scope of items covered: 1-project stakeholders (people/patients, health-care providers, health managers/policy-makers, organizational managers and researchers), 2-stakeholder involvement in the research process (selecting the research topic, study design, implementation, evaluation and dissemination of project results), 3-the ways of dissemination of results among the stakeholders (holding training workshops, conferences, radio, television and internet-based programs, using pamphlets, bulletins or newsletters, reports, policy briefs, etc.), 4-type of changes for each stakeholder groups, 5-Extent of changes (low, moderate, high), 6-predictability of changes (yes or no) 7-measures taken for sustainability (yes or no) 8-Time of change (during implementation, 1-3 years, 3-5 years or more than 5 years after project) 9-obstacles of change and 10-appropriate solutions for putting the research results into practice for different stakeholders.

The types of changes experienced in the people/patient group were considered as: informing about projects by training programs (nominal participation), participating in completion of each stage (instrumental participation), participation of representatives in the project stages (representative participation), empowerment (participation in decision-making), justice and equality (equal accessibility of health facilities and services to everyone regardless of gender, race, religion, etc.), and ownership (sense of ownership and responsibility towards the research process). In the researchers' group, the changes included: capacity building (improving skills and abilities of individuals and communities) and knowledge sharing (sharing and dissemination of information and knowledge among individuals).

In the policy-makers group changes included developing policymaking guides (guidelines, manuals, etc.). In the organizational managers group, these changes included managerial decision-making and inter-sectoral collaboration. In the health-care providers group, the changes concerned the type of service and the way in which it is provided.

Open-ended questions were used to extract the obstacles and solutions to improving KT in participatory research. The comprehension of items on the part of respondents was examined through a pilot study on 20 subjects. Then, content validity of the questionnaire was evaluated by employing expert opinion. At the next stage, Also, the reliability of the questionnaire was confirmed through the test-retest method $(\alpha=0$. 72).

The questionnaire was sent via email to the corresponding authors who were then interviewed by phone. Data collection lasted three months. During the phone call, the project objectives were firstly explained to the participants, to whom consent forms were sent via email. Data analysis was performed through descriptive statistics. The open items were analysed using qualitative content analysis. In this process, codes were firstly extracted directly and inductively from the raw data. Next, in each stakeholder group, the extracted codes were categorized into nine categories of problems and solutions.

\section{Results}

Among the 173 papers searched, duplicate and irrelevant studies were excluded based on their titles and abstracts. Of the remaining 94 papers, 79 were excluded due to failures to comply with the principles of participatory research. Finally, 28 papers were included in crosssectional study (Figure 1) from which $89.3 \%$ of the included papers were in Persian and $10.7 \%$ were in English. The evaluation indicated that $35.7 \%$ of studies involved intervention (non-clinical trial), $28.6 \%$ were descriptive, $10.7 \%$ were clinical trials and $25 \%$ were qualitative.

\section{Description of participants}

$61.5 \%$ of respondents were female, while the remaining $38.5 \%$ were male. $100 \%$ of respondents were academics, $38.4 \%$ of whom worked at research centers, $38.5 \%$ at universities, $7.7 \%$ at hospitals/medical education centers and $15.3 \%$ at the Ministry of Health and Medical Education.

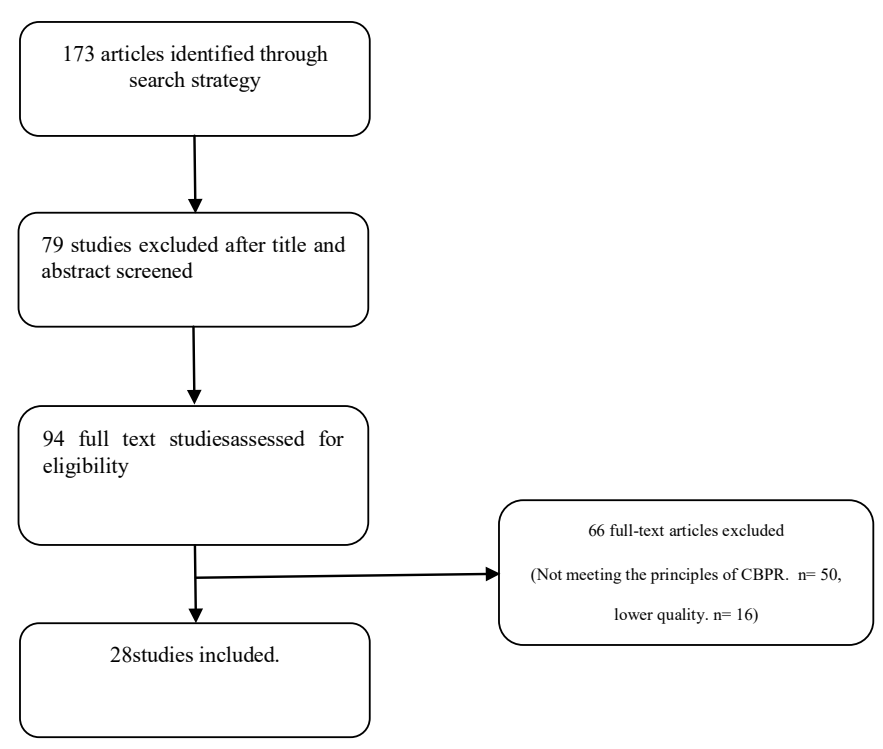

Figure 1. Flowchart of included articles 


\section{Knowledge translation aspects of CBPR studies}

The participants responded to questions about the project from which the paper derived. The respondents believed that the highest number of stakeholders in their research projects were people/patients (100\%) followed by researchers $(84 / 6 \%)$.

The results indicated that the majority of respondents $(61.6 \%)$ mentioned four groups or more as stakeholders.

The results showed that people/patients were involved in the study design of $100 \%$ of the research projects. The health managers/policymakers were involved in the dissemination of results (69.2\%), while the organizational managers $(38.5 \%)$, health-care providers $(38.5 \%)$ and researchers $(69.2 \%)$ made the greatest contribution during the process of project implementation.

The findings indicated that the results of participatory studies were disseminated to the people/patients group by printed media $(69.2 \%)$, and mass media (61.5\%). In the health-care providers group, the results were communicated through short reports and to organizational managers $(100 \%)$ followed by print media (30.5\%). In the health managers/policy-makers group, the results were presented through mass media (100\%), and sending short reports to managers $(53.5 \%)$. In the researchers' group, mass media were used to communicate the research results $(100 \%)$.

The results show that in the people/patients group, most changes occurred at the participation (92.3\%), empowerment (76.9\%) and informing $(69.2 \%)$ levels of participation. In health-care providers group, the greatest changes occurred at participation and informing $(30.8 \%)$ levels.

In the health managers/policy-makers group, the most changes occurred in inter-sectoral collaboration (38.5\%) and decision-making (30.8\%). In the organizational managers' group, the respondents assigned the highest scores of changes to inter-sectoral collaboration (53.8\%), decision-making and expansion of knowledge sharing (38.5\%) and policy-making $(30.8 \%)$. In the researchers' group, the greatest changes were reported in their levels of participation, capacity building and knowledge sharing (38.5\%).

The findings mentioned that in the researcher's group, changes occurred in more than seven areas (empowerment, participation, capacity building, knowledge sharing, knowledge, attitude and practice) (23.1\%).

Based on our findings, changes were extensive in stakeholders' participation in five studies (38.5\%), as well as changes related to empowerment and knowledge sharing in three studies $(23.1 \%)$. The rate of change was moderate in inter-sectoral collaboration as well as in decision-making, empowerment, participation, ownership, knowledge, attitude and practice at $30.8 \%$ (Table 1 ).

From the perspective of respondents, the actions taken to maintain and sustain the changes were reported mostly in the areas of decisionmaking, empowerment, participation, and knowledge in $23.1 \%$ of studies and the respondents mentioned most changes took place during the project implementation stage.

Table 2 displays the reasons for the non-occurrence of changes and suggests solutions from the perspective of respondents for increasing the use of research results in different groups of stakeholders.

\section{Discussion}

This study attempted to determine how the results of participatory research conducted through a participatory research approach in Iran are put into practice and to propose solutions for improving the KT process.

Results showed that the largest stakeholder groups were people/ patients, researchers, health managers/policymakers and health-care providers, consequently. In CBPR studies people are considered as the main stakeholders since they are more frequently affected by the issues of concern [20], a fact that has also been confirmed in this study.

The findings related to engaging stakeholders in the research process revealed that people and researchers were the most frequently involved stakeholders in all project stages, while organizational managers and policy-makers were mostly involved in the dissemination of results. Inconsistent with the results of this study, the review of relevant papers showed the involvement of researchers and people in defining the research question and recruiting voluntary participants, as well as at the design, implementation of intervention and interpretation of findings stages $[19,21]$.

Table 1. The extent of changes according to stakeholder groups from the perspectives of corresponding authors

\begin{tabular}{|c|c|c|c|c|c|}
\hline Stakeholder group & $\begin{array}{l}\text { The extent of changes } \\
\text { Type of Changes }\end{array}$ & $\begin{array}{c}\text { Low } \\
\text { n (\%) } \\
\text { N=13 }\end{array}$ & $\begin{array}{c}\text { Moderate } \\
\text { n (\%) } \\
\mathbf{N}=13\end{array}$ & $\begin{array}{l}\text { High } \\
\text { n (\%) }\end{array}$ & $\begin{array}{c}\text { Unknown } \\
\text { n (\%) } \\
\mathbf{N}=13\end{array}$ \\
\hline \multirow{5}{*}{ 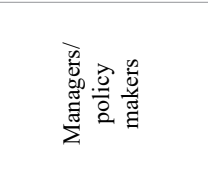 } & Policy making* & $2(15.4)$ & $1(7.7)$ & $2(15.4)$ & $8(61.5)$ \\
\hline & Decision making* & $1(7.7)$ & $4(30.8)$ & - & $8(61.5)$ \\
\hline & Type and ways of service delivery* & - & - & $2(15.4)$ & $11(84.6)$ \\
\hline & Practice* & $1(7.7)$ & $4(30.8)$ & $1(7.7)$ & $7(53.8)$ \\
\hline & Inter-sectoral collaboration* & - & $6(46.2)$ & $1(7.7)$ & $6(46.2)$ \\
\hline \multirow{6}{*}{ 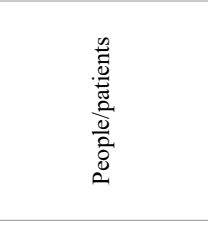 } & Empowerment** & $1(7.7)$ & $4(30.8)$ & $3(23.1)$ & $5(38.5)$ \\
\hline & Participation** & $1(7.7)$ & $4(30.8)$ & $5(38.5)$ & $3(23.1)$ \\
\hline & Equity** & - & $3(23.1)$ & $1(7.7)$ & $9(69.2)$ \\
\hline & Knowledge** & $1(7.7)$ & $4(30.8)$ & $2(15.4)$ & $6(46.2)$ \\
\hline & Ownership** & - & $4(30.8)$ & $1(7.7)$ & $8(61.5)$ \\
\hline & Attitude** & $2(15.4)$ & $4(30.8)$ & - & $7(53.8)$ \\
\hline \multirow{2}{*}{ 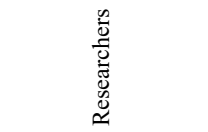 } & Capacity building*** & $2(15.4)$ & $3(23.1)$ & $1(7.7)$ & $7(53.8)$ \\
\hline & Knowledge sharing ${ }^{* * *}$ & - & $3(23.1)$ & $3(23.1)$ & $7(53.8)$ \\
\hline
\end{tabular}


Table 2. Problems and proposed solutions to strengthen the utilization of research results in different groups of stakeholders

\begin{tabular}{|c|c|c|c|c|c|c|c|c|c|}
\hline \multicolumn{2}{|r|}{ People / patients } & \multicolumn{2}{|c|}{$\begin{array}{l}\text { Health-care providers (nurses, } \\
\text { physicians, midwives, etc.) }\end{array}$} & \multicolumn{2}{|c|}{$\begin{array}{l}\text { Health managers / policy- } \\
\text { makers }\end{array}$} & \multicolumn{2}{|c|}{$\begin{array}{c}\text { Organizational Managers (welfare } \\
\text { Org, municipalities, Education } \\
\text { Org, etc.) }\end{array}$} & \multicolumn{2}{|c|}{ Researchers } \\
\hline Problem & Solution & Problem & Solution & Problem & Solution & Problem & Solution & Problem & Solution \\
\hline \multirow{3}{*}{ 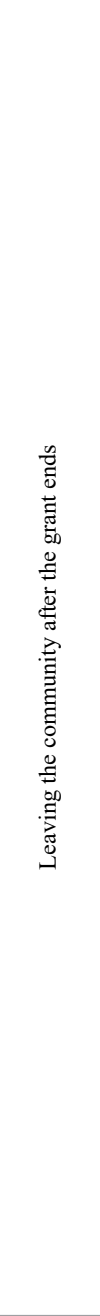 } & \multirow{3}{*}{$\begin{array}{l}\text {-Collaborative data analysis } \\
\text { and dissemination with the } \\
\text { community that improves } \\
\text { their ownership Following up } \\
\text { the research participants after } \\
\text { the project } \\
\text {-Voluntary involvement of } \\
\text { community members and } \\
\text { stakeholders in the design and } \\
\text { conduct of programs } \\
\text {-Sharing information on the } \\
\text { practice and results through } \\
\text { local media outlets } \\
\text {-Mobilization and } \\
\text { reorganization of community } \\
\text { in priority topics after } \\
\text { completion project cycle } \\
\text {-Training of community } \\
\text { members about } \\
\text { implementation and research } \\
\text {-Assessing the new needs } \\
\text { of the target population } \\
\text { and defining new culturally } \\
\text { supported interventions } \\
\text { - Designing attractive } \\
\text { messages from the results and } \\
\text { the ways for applying them }\end{array}$} & \multirow{3}{*}{ 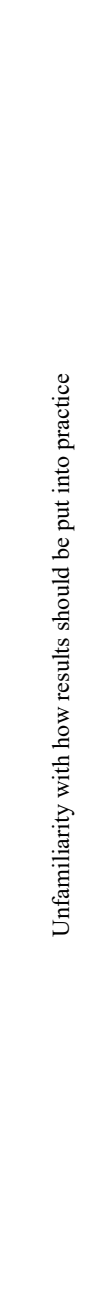 } & \multirow{3}{*}{$\begin{array}{l}\text {-Preparation of } \\
\text { practical guidelines } \\
\text { and training } \\
\text { packages } \\
\text {-Increasing } \\
\text { knowledge of health } \\
\text { service providers to } \\
\text { apply the results } \\
\text {-Capacity building } \\
\text { in service providers } \\
\text { for collaborative } \\
\text { working }\end{array}$} & \multirow{3}{*}{ 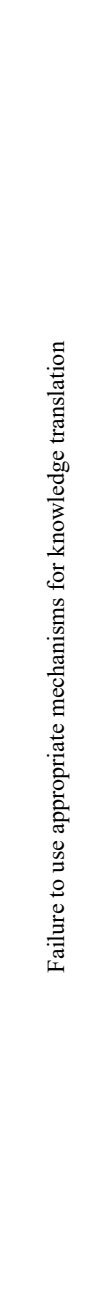 } & \multirow{3}{*}{$\begin{array}{l}\text {-Capacity building } \\
\text { to improve } \\
\text { commitment in } \\
\text { managers and } \\
\text { policy-makers to } \\
\text { utilize research } \\
\text { findings. } \\
\text {-Providing a } \\
\text { continuous feedback } \\
\text { system } \\
\text {-Engagement on } \\
\text { the part of policy- } \\
\text { makers since the } \\
\text { initial problem } \\
\text { statement } \\
\text {-Preparing a } \\
\text { summary of results } \\
\text { for adoption } \\
\text {-Devising } \\
\text { supportive policies } \\
\text { and structures } \\
\text { for participatory } \\
\text { research so } \\
\text { that knowledge } \\
\text { translation is } \\
\text { strengthened and } \\
\text { continued. }\end{array}$} & 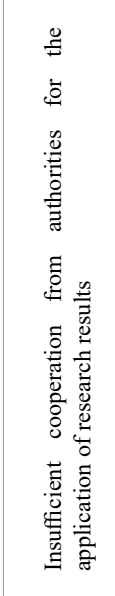 & $\begin{array}{l}\text {-Advocacy for } \\
\text { managerial corporate } \\
\text { support and lobbying } \\
\text { for the adoption of } \\
\text { results } \\
\text {-Greater attention to } \\
\text { corporate interests } \\
\text {-partnership building } \\
\text { of organizations under } \\
\text { land-use planning } \\
\text { - putting priorities in } \\
\text { the agenda and annual } \\
\text { operating plans of } \\
\text { organizations }\end{array}$ & 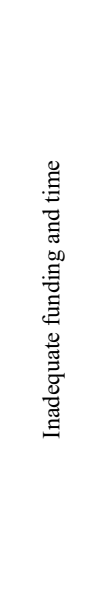 & $\begin{array}{l}\text {-Persistence in } \\
\text { participatory } \\
\text { research projects } \\
\text { funding through } \\
\text { integration with } \\
\text { existing programs } \\
\text {-Resource } \\
\text { mobilization and } \\
\text { attracting external } \\
\text { funding support } \\
\text { for knowledge } \\
\text { translation activities } \\
\text { - Considering } \\
\text { research translation } \\
\text { as an iterative } \\
\text { process and } \\
\text { defining long term } \\
\text { continuous projects }\end{array}$ \\
\hline & & & & & & 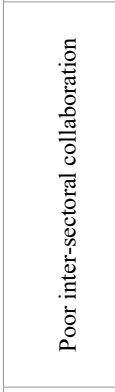 & $\begin{array}{l}\text {-Creating a sense of } \\
\text { trust by dialogue and } \\
\text { reflection fostered } \\
\text { by CBPR. between } \\
\text { organizations to } \\
\text { enhance knowledge } \\
\text { translation throughout } \\
\text { partnerships networks } \\
\text { - Using formal } \\
\text { agreements and } \\
\text { Memorandums } \\
\text { - }\end{array}$ & 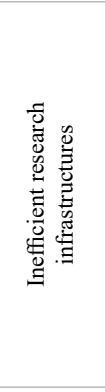 & $\begin{array}{l}\text {-Defining a web- } \\
\text { based KT plan } \\
\text { format for principal } \\
\text { investigators for } \\
\text { submitting their } \\
\text { plans and allocating } \\
\text { budget for approved } \\
\text { plans }\end{array}$ \\
\hline & & & & & & 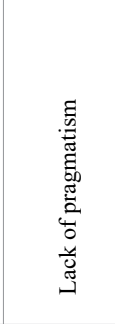 & $\begin{array}{l}\text {-Developing an annual } \\
\text { operational plan }\end{array}$ & 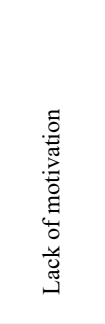 & $\begin{array}{l}\text { Valuing and } \\
\text { rewarding research- } \\
\text { based knowledge } \\
\text { translation efforts } \\
\text { in the promotion } \\
\text { and tenure process } \\
\text { to encourage } \\
\text { researchers to } \\
\text { apply results of } \\
\text { community-engaged } \\
\text { research }\end{array}$ \\
\hline
\end{tabular}

In the people group, the project results were disseminated mostly through pamphlets, bulletins, and newsletters; through short reports in the health-care providers group; through mass media in the policymakers, organizational managers and researchers groups. In the study by Nedjat et al. sending reports to stakeholders was a more frequent measure than the paper publication [22]. It seems that dissemination of knowledge mostly reported as a unilateral effort.

Participants reported empowerment as the greatest change that is occurred in the group of people/patients, while in the health managers/ policy-makers groups changes occurred in policies and inter-sectoral collaboration. In a study conducted in Hong Kong, 35.4\% and in the studies conducted in Australia and the UK 31\% and 13\% of researches affected the formation of policies (including guidelines and protocols) and the other steps of the policy-making process, respectively $[14,15]$. Consistent with the findings, the overview of successful models of CBPR indicates that this type of research has a positive impact on the empowerment of the community in identifying and solving their problems and collaborative action to change policies [23,24].
Results showed that in the organizational managers' group, the greatest changes were attributed to the areas of inter-sectoral collaboration, managerial decision-making, and knowledge sharing. The overview of case studies conducted via participatory research demonstrated the effects of this approach on inter-sectoral collaboration, the formation of inter-organizational networks and knowledge sharing $[25,26]$.

The findings indicated that the most reported changes in the researchers' group were related to improving participation, knowledge sharing, and capacity building. The findings of Reed et al. show the positive impact of research on the capacity of health researchers [15]. The findings of Malek Afzali et al. show that the academics who involved in CBPR projects, assigned high scores to co-learning, opportunities to participate in research, and reaching agreement on the dissemination of findings [27], which is consistent with the findings of this study.

Participants reported that projects had a high impact on the participation and a moderate impact on the inter-sectoral collaboration, managerial decision-making, empowerment, ownership, knowledge, 
and attitude and practice areas. In a systematic review, changes were also related to knowledge and attitude (HIV/AIDS prevention), capacity building and community participation (screening by Pap smear), intersectoral collaboration (creating healthy villages), behavior/practice (increased use of condoms, healthy food) [21].

The results showed that the major obstacles to the adoption of research results in most areas were lack of time, inadequate funding, and the weakness of existing infrastructures. Wallerstein et al. similarly pointed out insufficient funds to sustaining the research results as an obstacle [24]. Other studies mentioned the challenges such as lack of time and budget too $[28,29]$. Moreover, Nedjat et al. pointed to the ineffective research infrastructures to disseminate research results as one of the major obstacles [30].

From the solutions proposed by participants for different groups of stakeholders, some recommendations can be summarized:

1. Adoption of an appropriate communication strategy for each group of stakeholders.

2. Engaging the stakeholders at all stages, capacity building on knowledge translation practices.

3. Outlining flexible organizational structures that enable collaboration and teamwork.

4. Adoption of a plan-oriented, long-term approach to implementation of research results.

\section{Conclusion}

CBPR can have a great impact on community participation in the research process, as well as on capacity building and knowledge sharing among researchers. It can also have moderate effects on improving managerial decision-making and inter-sectoral collaboration among organizational managers. However, there are certain obstacles in practice which have been explored in this study and some solutions are proposed.

\section{Limitations}

The limitations of this study were the number of papers and the fact that not all researchers in this field had published the outputs of their works in the form of a paper. Thus, the results can barely be generalized. Another limitation is the unavailability of corresponding authors for reasons such as incorrect email addresses or phone numbers, unwillingness to participate in the interview, or failure to answer the phone/emails. Also, the research questions were asked from the corresponding authors, but it would have been better if the research team had asked questions directly from the stakeholder groups of the projects. This could create a triangulation to enrich and validate the data.

\section{Acknowledgements} study.

We thank corresponding authors of articles who participate in this

\section{Authors' contributions}

Conceived, development and design of methodology in the study: NL, EJ, JA, KM and RM. Helped to data collection: NL and EJ. Analyzed the data: EJ, JA, KM and NHG. Wrote the paper: NL, EJ, KM and JA. All authors read and approved the final manuscript.

\section{Funding}

This research has been supported by I. R. Iran's National Institute of Health Research, Tehran University of Medical Sciences and Health Services grant No. 91281. The funders had no role in the design and conduct of the study, collection, management, analysis, and interpretation of the data, preparation, review, approval of the manuscript, and decision to submit the manuscript for publication.

\section{Availability of data and materials}

The datasets generated during the current study available from the corresponding author on reasonable request.

\section{Ethics approval and consent to participate}

This research was ethically approved by the research committee of I. R. Iran's National Institute of Health Research, Tehran University of Medical Sciences No. 91281. Informed consent forms were completed and the Declaration of Helsinki was followed in all stages of the research.

\section{Consent for publication}

Not applicable.

\section{Competing interests}

The authors declare that they have no competing interests.

\section{References}

1. Jull J, Giles A, Graham ID (2017) Community-based participatory research and integrated knowledge translation: advancing the co-creation of knowledge. Implement Sci 12: 150 .

2. Graham ID, Logan J, Harrison MB, Straus SE, Tetroe J, et al. (2006) Lost in knowledge translation: time for a map? Journal of Continuing Education in the Health Professions 26: $13-24$.

3. Israel BA, Schulz AJ, Parker EA, Becker AB (1998) Review of community-based research: assessing partnership approaches to improve public health. Annual Review of Public Health 19: 173-202.

4. Salsberg J, Ma C (2008) Integrating knowledge translation through participatory research. In: University DoFM-M, editor. Participatory Research at McGill University (PRAM) 2008, June

5. Collaborative CU (2006) A manual for community based particpatory research. Center for Excellence in Assisted Living (CEAL) and the University of North Carolina (UNC).

6. Shahandeh K, Jamshidi E, Akbari F, Adili F, Esmailzadeh H (2006) Participatory research of lifestyle of residents in zone 17 Tehran in 1385 (In Persian). Journal of Arak University of Medical Sciences 9: 36-45.

7. Jamshidi E, Majdzadeh R, Namin MS, Ardalan A, Majdzadeh B, et al. (2016) Effectiveness of community participation in earthquake preparedness: a communitybased participatory intervention study of Tehran. Disaster Medicine and Public Health Preparedness 10: 211-218.

8. Jamshidi E, Loori N, Shahandeh K, Jamshidi T (2012) Improving patient's rights through participation in guideline development: A community based participatory research approach. Iranian Journal of Medical Law 1:50-4.

9. Hosseini SV, Anoosheh M, Ahmadi F (2008) The Effect of Adolescents' Participation on Sanitary Collection and Disposal of Garbage (In Persian). Iran Journal of Nursing 21: 9-17.

10. Malekaftali H, Bahreini F, Forouzan A(2011) Community Based Participatory Research in Iran: Challenges and the ways to control it from the viewpoints of stakeholders (In Persian). Journal of Research and Health 1: 10-16.

11. Kolahi AA (2015) Introduction of the Research Network of Defined Population Affiliated by the Social Determinants of Health Research Center of Shahid Behesht University of Medical Sciences: Structure and Start up Methodology. Community Health 1: 1-10.

12. Qorbani M, Borghei A, Keshtkar A, Majdzadeh R, Nedjat S, et al. (2010) Knowledge transfer in Golestan University of Medical Sciences projects in 2005-2007 (In Persian) Hakim Research Journal 12: 19-26. 
13. Kwan P, Johnston J, Fung AY, Chong DS, Collins RA, et al. (2007) A systematic evaluation of payback of publicly funded health and health services research in Hong Kong. BMC Health Services Research 7: 1.

14. Hanney SR, Watt A, Jones TH, Metcalf L (2013) Conducting retrospective impact analysis to inform a medical research charity's funding strategies: the case of Asthma UK. Allergy, Asthma \& Clinical Immunology 9: 1.

15. Reed RL, Kalucy EC, Jackson-Bowers E, McIntyre E (2011) What research impacts do Australian primary health care researchers expect and achieve? Health Research Policy and Systems 9: 1.

16. Wooding S, Hanney SR, Pollitt A, Grant J, Buxton MJ (2014) Understanding factors associated with the translation of cardiovascular research: a multinational case study approach. Implementation Science 9: 1.

17. Yazdizadeh B, Majdzadeh R, Janani L, Mohtasham F, Nikooee S, et al. (2016) An assessment of health research impact in Iran. Health Research Policy and Systems 14: 1.

18. Schulz AJ, Parker EA (2005) Methods in community-based participatory research for health. San Francisco: Jossey-Bass.

19. Viswanathan M, Ammerman A, Eng E, Garlehner G, Lohr KN, et al (2004) Communitybased participatory research: Assessing the evidence: Summary US: Agency for Healthcare Research and Quality (US), Rockville (MD).

20. Minkler M (2005) Community-based research partnerships: challenges and opportunities. Journal of Urban Health 82: ii3-ii12.

21. Salimi Y, Shahandeh K, Malekafzali H, Loori N, Kheiltash A, et al. (2012) Is community-based participatory research (CBPR) useful? A systematic review on papers in a decade. International Journal of Preventive Medicine 3: 386.
22. Nedjat S, Majdzadeh R, Gholami J, Qorbani M, Nedjat S, et al. (2008) Need to review the criteria for faculty evaluation: A study of knowledge transfer from research at Tehran University of Medical Sciences. Journal of Medical Council of Iran 4: 169-180.

23. Minkler M, Garcia A, Rubin V, Wallerstein N (2012) Community-based participatory research: A strategy for building healthy communities and promoting health through policy change, a report to the California endowment. University of California, Berkeley School of Public Health: Policy Link.

24. Wallerstein N, Duran B (2010) Community-based participatory research contributions to intervention research: the intersection of science and practice to improve health equity. American Journal of Public Health 100: S40-S46.

25. Minkler M, Breckwich V, Chang C, Miller J (2009) Promoting healthy public policy through community-based participatory research: Ten case studies. University of California, Berkeley School of Public Health: Policy Link.

26. Danaher A (2011) Reducing Health Inequalities: Enablers and barriers to inter-sectoral collaboration. Toronto: Wellesly Institute June 4.

27. Malekafzali H, Forouzan A, Eftekhari MB, Farahani MA, Vishteh H (2009) Community-Based Participatory Research: How Do Academicians Rate Success in Iran? Iran J Public Health 38: 54-57.

28. Oakes JM, Kaufman JS (2006) Methods in social epidemiology: John Wiley \& Sons.

29. Jamshidi E, Morasae EK, Shahandeh K, Majdzadeh R, Seydali E, et al. (2014) Ethical considerations of community-based participatory research: Contextual underpinnings for developing countries. International Journal of Preventive Medicine 5: 1328.

30. Nedjat S, Nedjat S, Gholami J, Ashoorkhani M, Maleki K, et al. (2009) How much has knowledge transfer been observed in the health programs? (In Persian). Hakim Research Journal 4: 1-7.

Copyright: (C2020 Loori N. This is an open-access article distributed under the terms of the Creative Commons Attribution License, which permits unrestricted use, distribution, and reproduction in any medium, provided the original author and source are credited. 